Research Article

\title{
Molecular Confirmation of Vancomycin-Resistant Staphylococcus aureus with vanA Gene from a Hospital in Kathmandu
}

\author{
Meera Maharjan, ${ }^{1}$ Anil Kumar Sah ${ }^{1},{ }^{2}$ Susil Pyakurel $(1),{ }^{3}$ Sabita Thapa, ${ }^{1}$ Susan Maharjan, ${ }^{1}$ \\ Nabaraj Adhikari $\left(\mathbb{D},{ }^{4}\right.$ Komal Raj Rijal $\mathbb{D}^{4}{ }^{4}$ Prakash Ghimire $\mathbb{D}^{4}{ }^{4}$ \\ and Upendra Thapa Shrestha
}

${ }^{1}$ Department of Microbiology, Kantipur College of Medical Science, Sitapaila, Kathmandu, Nepal
${ }^{2}$ Department of Microbiology, Annapurna Neurological Institute and Allied Sciences, Maitighar, Kathmandu, Nepal
${ }^{3}$ Department of Microbiology, Shi-Gan International College of Science and Technology, Kathmandu, Nepal
${ }^{4}$ Central Department of Microbiology, Tribhuvan University, Kirtipur, Nepal

Correspondence should be addressed to Upendra Thapa Shrestha; upendrats@gmail.com

Received 17 September 2021; Revised 3 November 2021; Accepted 20 November 2021; Published 2 December 2021

Academic Editor: Carlo Genovese

Copyright (c) 2021 Meera Maharjan et al. This is an open access article distributed under the Creative Commons Attribution License, which permits unrestricted use, distribution, and reproduction in any medium, provided the original work is properly cited.

\begin{abstract}
Staphylococcus aureus, a commensal on the skin and in the nasal cavity of humans, is one of the most serious cases of nosocomial infections. Moreover, methicillin-resistant S. aureus (MRSA) is a leading cause of morbidity and mortality worldwide. For the treatment of MRSA infections, vancomycin is considered as a drug of choice. However, the emergence of vancomycin resistance among MRSA isolates has been perceived as a formidable threat in therapeutic management. To estimate the rate of vancomycin-resistant $S$. aureus (VRSA) and to detect the vancomycin-resistant genes, namely, $v a n A$ and $v a n B$, among the isolates, a hospital-based cross-sectional study was conducted from July to December 2018 in Annapurna Neurological Institute and Allied Science, Kathmandu, Nepal. S. aureus was isolated and identified from different clinical samples and processed for antibiotic susceptibility testing by the modified Kirby-Bauer disc diffusion method. The screening of MRSA was performed as per Clinical and Laboratory Standard Institute (CLSI) guidelines. VRSA was confirmed by the minimum inhibitory concentration (MIC) method by employing E-test strips. All the phenotypically confirmed VRSA were further processed to detect the $v a n A$ and $v a n B$ gene by using the conventional polymerase chain reaction (PCR) method. A total of 74 (20.3\%) S. aureus were isolated, and the highest percentage of S. aureus was from the wound samples (36.5\%). Of 74 S. aureus isolates, the highest number $(89.2 \%)$ was resistant to penicillin, and on the other hand, linezolid was found to be an effective drug. Likewise, 45 (60.81\%) were found to be MRSA, five (11.11\%) were VRSA, and 93.2\% of S. aureus isolates showed an MAR index greater than 0.2. Two VRSA isolates (40\%) were positive for the vanA gene. The higher prevalence of MRSA and significant rate of VRSA in this study recommend routine surveillance for the MRSA and VRSA in hospital settings before empirical therapy.
\end{abstract}

\section{Introduction}

Staphylococci are the most commonly isolated organisms, accounting for almost $30 \%$ of all hospital-acquired infections and $50 \%$ of bloodstream infections $[1,2]$, and have become a major public health threat as a result of increased drug resistance in this organism [3]. Staphylococcal resistance to antimicrobial agents is a worldwide concern with a history of almost 70 years. Penicillin was an effective drug to treat
Staphylococcus aureus until the emergence of methicillinresistant S. aureus (MRSA) in England in 1961 [4]; since then, MRSA has been reported as a leading cause of nosocomial infections [5]. Vancomycin is a choice of drug for the treatment of MRSA infections, which has resulted in the development of vancomycin-intermediate $S$. aureus (VISA) and vancomycin-resistant S. aureus (VRSA). In May 1996, the first VISA was reported in Japan [6]. Since then, VRSA strains were isolated in USA, Australia, Europe, and other 
Asian countries [7]. This resistance might be acquired by both mutation and/or the horizontal transfer of vancomycin-resistant genes among the bacteria [8]. Till now, 11 van genes, vanA, vanB, vanD, vanF, vanI, vanM, vanC, vanE, $v a n G$, vanL, and $v a n N$, have been described [9]. Among them, van $A$ and $v a n B$ genes are the most important and commonly observed in hospital isolates. The vanA gene is highly resistant to vancomycin and teicoplanin antibiotics, while the $v a n B$ gene shows higher resistance to vancomycin and susceptibility to teicoplanin [10]. Although VRSA remains rare, there is a global concern that VRSA poses by far the risk to the patient due to its virulent nature. This virulent nature of the organism with limited treatment options makes VRSA a global public threat [11]. According to the $\mathrm{WHO}$, the pathogenicity and resistance patterns of $S$. aureus pose a great threat to global health. In addition, the resistant strains of $S$. aureus, MRSA, VISA, and VRSA, are recently classified as bacteria of high priority with the potential to cause significantly devastating mortality globally if adequate treatment options are not developed [12].

In Nepal, the prevalence of MRSA showed an increasing trend: $29.1 \%-68 \%$ [13-15]. On the other hand, comparatively few works on the detection of VISA, VRSA, and their encoding genes have been conducted $[15,16]$. Therefore, the present study was aimed to detect the VRSA and their encoding genes, namely, vanA and vanB, among VRSA isolates obtained from different clinical specimens. In addition, the information obtained from our study can be utilized to formulate national antibiotic policy and appropriate control measures for further spread of VRSA.

\section{Materials and Methods}

2.1. Study Design. A hospital-based cross-sectional study was conducted among patients of Annapurna Neurological Institute and Allied Sciences, Kathmandu, Nepal, from July to Dec 2018. The study was approved by the Nepal Health and Research Council (NHRC). The sample size was calculated by using Fisher's formula. Patients of all age groups and sexes visiting the hospital during the study period who gave written consent to be enrolled were included for data and specimen collections. A total of 795 clinical samples were collected including urine $(n=279)$, sputum $(n=126)$, blood $(n=118)$, pus $(n=109)$, wound swab $(n=92)$, and others ( $n=71$; catheter tips, cerebrospinal fluid (CSF), synovial fluid, and ventriculoperitoneal shunt tips). Those samples showing the possible signs of contaminations were excluded from the study.

2.2. Sample Collection. Samples were collected according to standard laboratory protocols [17]. All valid specimens were cultured on suitable culture media as per their requirements.

2.3. Identification of $S$. aureus. Gram-positive organisms with grape-like clusters on microscopy and yellow colonies on mannitol salt agar (MSA) were primarily screened as $S$. aureus and were confirmed by performing different biochemical tests including catalase, coagulase, and oxidase tests $[17,18]$. All the isolates confirmed as $S$. aureus were used for further analysis.

2.4. Antimicrobial Susceptibility Testing (AST). All the identified $S$. aureus isolates were subjected to an in vitro antimicrobial susceptibility test by employing the modified Kirby-Bauer disc diffusion method as recommended by Clinical and Laboratory Standard Institute (CLSI) guidelines [19]. The antimicrobial disks used were ampicillin $(30 \mu \mathrm{g})$, cefoxitin $(30 \mu \mathrm{g})$, chloramphenicol $(30 \mu \mathrm{g})$, ciprofloxacin $(25 \mu \mathrm{g})$, clindamycin $(31 \mu \mathrm{g})$, cotrimoxazole $(25 \mu \mathrm{g})$, erythromycin $(26 \mu \mathrm{g})$, gentamycin $(28 \mu \mathrm{g})$, linezolid $(30 \mu \mathrm{g})$, oxacillin $(10 \mu \mathrm{g})$, tetracycline $(20 \mu \mathrm{g})$, and penicillin $(10 \mu \mathrm{g})$ from HiMedia, India.

2.5. Screening of MRSA and VRSA. S. aureus with a zone of inhibition size of $21 \mathrm{~mm}$ or less with a cefoxitin $(\mathrm{CX} 30 \mu \mathrm{g})$ disc was screened as MRSA and having a zone size of $16 \mathrm{~mm}$ or less with vancomycin $(30 \mu \mathrm{g})$ was considered as VRSA as per CLSI guidelines [19].

2.6. Confirmation of VRSA by MIC Using Vancomycin Strips (E-Test). Carpet cultures of bacterial suspension were performed over the Mueller Hinton agar (MHA) plate. The E-test strip (HiMedia) was placed on an MHA plate with an MIC scale facing upward and the concentration maximum nearest to the rim of the plate. Then, the plates were incubated for $24 \mathrm{~h}$ at $37^{\circ} \mathrm{C}$, and the zone of inhibition was measured [20]. The isolates were interpreted as vancomycinsensitive $S$. aureus (VSSA), VISA, and VRSA if the size of zone of inhibition was $\geq 20 \mathrm{~mm}, 17-19 \mathrm{~mm}$, and $\leq 16 \mathrm{~mm}$, respectively. VRSA isolates were preserved in $20 \%$ glycerol containing tryptic soya broth and kept at $-70^{\circ} \mathrm{C}$ until subsequent molecular tests were performed [21].

2.7. Molecular Detection of vanA and vanB Gene. The extraction of DNA (plasmid) of VRSA isolates was carried out by using the lysostaphin lysis method [22]. Genes encoding the vancomycin resistance determinants, van $A$ and $v a n B$, were detected by conventional polymerase chain reaction (PCR) (Proflex, Thermo Fisher, USA) using specific primers manufactured by Macrogen Korea. The primers used were vanA F-GGCAAGTCAGGTGAAGATG, vanA R-ATCAAGCGG TCAATCAGTTC, vanB F-GTGACAAACCGGAGG CGAGGA, and $v a n B$ R- CCGCCATCCTCCTGCAAAAAA, respectively $[23,24]$. A total of $25 \mu \mathrm{l}$ PCR reaction mixture was used for amplification of each gene. The PCR amplification of the vanA gene was carried out at an initial denaturation for $2 \mathrm{~min}$ at $94^{\circ} \mathrm{C}$ followed by 35 cycles of denaturation at $94^{\circ} \mathrm{C}$ for $1 \mathrm{~min}$, annealing at $54^{\circ} \mathrm{C}$ for $1 \mathrm{~min}$, and extension at $72^{\circ} \mathrm{C}$ for $1 \mathrm{~min}$. The final extension had been 
performed at $72^{\circ} \mathrm{C}$ for 10 mins. Likewise, the $\operatorname{van} B$ gene was amplified at an initial denaturation at $94^{\circ} \mathrm{C}$ for $10 \mathrm{~min}$ followed by 30 cycles of denaturation at $94^{\circ} \mathrm{C}$ for $30 \mathrm{sec}$, annealing at $50^{\circ} \mathrm{C}$ for $45 \mathrm{sec}$, and extension at $72^{\circ} \mathrm{C}$ for $30 \mathrm{sec}$. The final extension was performed at $72^{\circ} \mathrm{C}$ for $6 \mathrm{~min}$. The obtained PCR products were electrophoresed in a $1.5 \%$ agarose gel which was stained with ethidium bromide $(0.3 \mu \mathrm{g} / \mathrm{ml})$, visualized by using a UV transilluminator [25]. The molecular weight of the amplified product was estimated using a 100 bp DNA ladder (Solis Biodyne, Estonia).

2.8. Quality Control. All the tests were carried out by following standard aseptic techniques and CLSI guidelines. S. aureus (ATCC 25923) was used to ensure the performance of newly prepared media and the quality control of the AST and E-test. Enterococcus fecalis ATCC 51299 was used as a vancomycin-resistant control strain for molecular detection of resistant genes.

2.9. Statistical Analysis. All the data were entered and analyzed by using Statistical Package for Social Science (SPSS) version 24.

\section{Results}

3.1. Distribution of S. aureus. Of the 795 samples processed, $45.8 \%$ (364/795) showed growth containing 42.3\% (154/364) Gram-positive bacteria. A total of $74 \mathrm{~S}$. aureus isolates were obtained from the different clinical samples. The highest percentage $(47.4 \%)$ was obtained from the wound swab followed by pus (41.0\%). Likewise, the maximum percentage of isolates was obtained among the patients from the ICU $(26.2 \%)$ followed by the Gynae ward (20.8\%). A higher number of female patients were found to be infected than male patients (Table 1).

3.2. Antimicrobial Susceptibility Testing of S. aureus. Out of 12 different antimicrobial drugs used for AST, linezolid was found to be the most effective antimicrobial drug with $97.3 \%$ effectiveness to S. aureus, followed by clindamycin (36.5\%) and gentamycin (36.5\%). The highest resistance was found to penicillin (89.2\%) and ampicillin (72.9\%). Out of 74 S. aureus, $45(60.8 \%)$ were found to be MDR (Table 2).

\subsection{Antimicrobial-Resistant Phenotypes and Antimicrobial} Resistance (MAR) Index. The highest number of isolates (35.1\%) showed resistance to 11 antimicrobial drugs out of 12 except for linezolid followed by $12.2 \%$ isolates showing resistance to 10 antimicrobials. Only one isolate was found to be sensitive to all antimicrobial drugs. Altogether, 30 different types of resistant phenotypes were observed in our study among 74 isolates (Table 3 ).
Likewise, $93.2 \%$ of $S$. aureus isolates achieved an MAR index greater than 0.2 (Table 4).

3.4. Detection of the vanA Gene. Based on the results of the E-test for vancomycin among $45 \mathrm{MRSA}$ isolates, the number VSSA, VISA, and VRSA was 25, 15, and 5, respectively (Figure 1). Of five VRSA-positive isolates, two isolates were found to be positive for the vanA gene whereas the $\operatorname{van} B$ gene was not detected in this study (Table 5 and Figure 2).

\section{Discussion}

Vancomycin is the main therapeutic choice to treat MSRA. The early 1990s have shown a discernible increase in vancomycin use, and its excessive use for MRSA led to decreased susceptibility to vancomycin $[26,27]$. However, in our study, we found $97.3 \%$ of $S$. aureus were sensitive to linezolid, so it can be the drug of choice for MRSA and VRSA strains. This study was in accordance with the work of Belbase et al. [28] which showed that all MRSA (100\%) were sensitive to linezolid. On the other hand, most (89.2\%) of the S. aureus isolates were resistant to penicillin. This result is similar to the previous works in Nepal $[29,30]$. Of 74 S. aureus isolates, 45 (60.81\%) isolates were MRSA. The finding of our study was consistent with other previous findings in Nepal [30-33]. However, the prevalence varies in the different parts of Nepal $[34,35]$ and India [36]. This finding can show the use of beta-lactam antibiotics against Gram-positive organisms in hospital and community settings. Although there are other antibiotics, including daptomycin and linezolid that may be effective against MRSA, increasing MRSA strains resistant to vancomycin have created a challenge in making clinical treatment decisions for such isolates [37]. Of $74 \mathrm{~S}$. aureus isolates, we observed 30 different types of resistant phenotypes and $93.2 \%$ of $S$. aureus isolates achieved an MAR index greater than 0.2 . This finding indicates the high-risk source of contamination due to continuous irrational use of antimicrobial drugs for empirical therapy in our hospital settings. Upon performing MIC, 5 (11.11\%) of the MRSA isolates were reported as vancomycin-resistant strains which is higher than that in the study by Lama et al. [38] in Nepal and Thati et al. in India [39]. However, a higher prevalence (44.5\%) of VRSA among MRSA isolates was reported in Nigeria [40]. Out of 5 VRSA, only 2 (40\%) isolates showed vanA genes and no vanB genes were detected. In comparison to the study, the study performed by Saadat et al. [41] showed $40 \%$ of the isolates harbored at least one of the van genes. The remaining three isolates might possess other van genes rather than $v a n A$ and $\operatorname{van} B$, which were used in our study due to limitation of budget.

The predominant S. aureus (20.32\%) out of 364 bacterial pathogens isolated in our study were confirmed by conventional phenotypic methods rather than the PCR method. As Nepal is a resource-limited country and most of the manpower have limited training, more advanced methods are used in some specific research activities only. Also, most 
TABLE 1: Distribution of MRSA and VRSA isolates.

\begin{tabular}{|c|c|c|c|c|c|}
\hline Organism/distribution & Growth positive, $n(\%)$ & Gram positive, $n(\%)$ & S. aureus, $n(\%)$ & MRSA, $n(\%)$ & VRSA, $n(\%)$ \\
\hline \multicolumn{6}{|l|}{ Sex } \\
\hline Male $(n=409)$ & $215(52.6)$ & $93(43.2)$ & $42(19.5)$ & $29(69.0)$ & $3(10.3)$ \\
\hline Female $(n=386)$ & $149(38.6)$ & $61(40.9)$ & $32(21.5)$ & $16(50.0)$ & $2(12.5)$ \\
\hline \multicolumn{6}{|l|}{ Clinical samples } \\
\hline Urine $(n=279)$ & $135(48.3)$ & $32(23.7)$ & $10(7.4)$ & $3(50.0)$ & 0 \\
\hline Sputum $(n=126)$ & $61(48.4)$ & $29(47.5)$ & $13(21.3)$ & $5(38.5)$ & 0 \\
\hline Blood $(n=118)$ & $20(16.9)$ & $7(35.0)$ & $6(30.0)$ & $2(33.3)$ & 0 \\
\hline Pus $(n=109)$ & $54(49.5)$ & $34(62.9)$ & $16(29.6)$ & $14(87.5)$ & $3(21.4)$ \\
\hline Wound swab $(n=92)$ & $57(61.9)$ & $42(73.7)$ & $27(47.4)$ & $21(77.8)$ & $2(9.5)$ \\
\hline${ }^{*}$ Others $(n=71)$ & $17(23.9)$ & $10(58.8)$ & $2(11.8)$ & 0 & 0 \\
\hline \multicolumn{6}{|l|}{ Hospital units } \\
\hline General ward $(n=370)$ & $160(43.2)$ & $66(41.3)$ & $32(20.0)$ & $20(62.5)$ & $2(10.0)$ \\
\hline OPD $(n=171)$ & $91(53.2)$ & $35(38.5)$ & $15(16.5)$ & $9(60.0)$ & $1(11.1)$ \\
\hline $\operatorname{ICU}(n=125)$ & $65(52.0)$ & $31(47.6)$ & $17(26.2)$ & $12(70.5)$ & $2(16.7)$ \\
\hline Gynae $(n=129)$ & $48(37.2)$ & $22(45.8)$ & $10(20.8)$ & $4(40.0)$ & 0 \\
\hline Total $(n=795)$ & $364(45.8)$ & $154(42.3)$ & $74(20.3)$ & $45(60.8)$ & $5(11.1)$ \\
\hline
\end{tabular}

Abbreviations: MRSA = methicillin-resistant Staphylococcus aureus; VRSA = vancomycin-resistant Staphylococcus aureus; ${ }^{*}$ others $=$ throat swab, vaginal swab, synovial fluid, and pleural fluid; percentage calculated on respective row total.

TABLe 2: Antimicrobial susceptibility patterns of $S$. aureus isolates $(n=74)$.

\begin{tabular}{lccc}
\hline Antimicrobial drugs & Sensitive, $n(\%)$ & Intermediate, $n(\%)$ & Resistant, $n(\%)$ \\
\hline Ampicillin & $11(14.9)$ & $9(12.2)$ & $54(72.9)$ \\
Cefoxitin & $29(39.2)$ & 0 & $45(60.8)$ \\
Chloramphenicol & $24(32.4)$ & $8(10.8)$ & $42(56.8)$ \\
Ciprofloxacin & $22(29.7)$ & $7(9.5)$ & $45(60.8)$ \\
Clindamycin & $27(36.5)$ & $6(8.1)$ & $41(55.4)$ \\
Cotrimoxazole & $22(29.7)$ & $5(6.8)$ & $47(63.5)$ \\
Erythromycin & $13(13.6)$ & $6(8.1)$ & $55(74.3)$ \\
Gentamycin & $27(36.5)$ & $5(6.8)$ & $42(56.7)$ \\
Linezolid & $72(97.3)$ & 0 & $2(2.7)$ \\
Oxacillin & $10(13.5)$ & 0 & $64(86.5)$ \\
Penicillin & $8(10.8)$ & 0 & $66(89.2)$ \\
Tetracycline & $18(24.3)$ & $2(2.7)$ & $54(73.0)$ \\
\hline
\end{tabular}

TABLE 3: Antimicrobial-resistant phenotypes of $S$. aureus isolates $(n=74)$.

\begin{tabular}{|c|c|c|c|}
\hline Resistant to no. of antimicrobial drugs & Resistant phenotypes & No. of isolates showing the pattern & Total no. of isolates (\%) \\
\hline 12 & AmpCxCCipCdCotEGenLzOxPTe & 2 & $2(2.7)$ \\
\hline 11 & AmpCxCCipCdCotEGenOxPTe & 26 & $26(35.1)$ \\
\hline 10 & $\begin{array}{c}\text { AmpCxCipCdCotEGenOxPTe } \\
\text { AmpCCipCdCotEGenOxPTe }\end{array}$ & $\begin{array}{l}1 \\
8\end{array}$ & $9(12.2)$ \\
\hline 9 & $\begin{array}{c}\text { AmpCCipCotEGenOxPTe } \\
\text { AmpCxCdCotEGenOxPTe } \\
\text { AmpCCipCdCotEGenOxTe } \\
\text { CxCCipCdCotEOxPTe }\end{array}$ & $\begin{array}{l}1 \\
1 \\
1 \\
1\end{array}$ & $4(5.4)$ \\
\hline 8 & $\begin{array}{c}\text { CCipCdCotEGenOxTe } \\
\text { AmpCCipEGenOxPTe } \\
\text { AmpCxCCipCotEOxTe }\end{array}$ & $\begin{array}{l}1 \\
1 \\
1\end{array}$ & $3(4.0)$ \\
\hline 7 & $\begin{array}{c}\text { CCipCdCotEOxP } \\
\text { CxCCipCdCotEOx } \\
\text { AmpCxEGenOxPTe } \\
\text { AmpCipCdCotEOxP }\end{array}$ & $\begin{array}{l}2 \\
3 \\
4 \\
1\end{array}$ & $10(13.5)$ \\
\hline 6 & $\begin{array}{l}\text { AmpCxGenOxPTe } \\
\text { CCipCdCotEOxTe }\end{array}$ & $\begin{array}{l}1 \\
1\end{array}$ & $2(2.7)$ \\
\hline
\end{tabular}


TABle 3: Continued.

\begin{tabular}{lccc}
\hline Resistant to no. of antimicrobial drugs & Resistant phenotypes & No. of isolates showing the pattern & Total no. of isolates (\%) \\
\hline 5 & CCipCotEPTe & 1 & 1 \\
& AmpCxOxPTe & 2 & $5(6.8)$ \\
& AmpEOxPTe & 1 & \\
& AmpCotEOxP & 1 & \\
4 & AmpCCipP & 1 & $5(6.8)$ \\
& AmpEOxP & 1 & \\
\hline 3 & AmpCxOxP & 1 & $3(4.0)$ \\
\hline 2 & AmpEPTe & 2 & \\
\hline 1 & AmpCxPTe & 1 & $3(4.0)$ \\
\hline Sensitive to antimicrobial drugs & AmpCxP & 3 & $1(1.4)$ \\
\hline Total & AmpP & 1 & $1(1.4)$ \\
\hline A & P & 1 & $\mathbf{7 4}$ \\
\hline
\end{tabular}

Amp, ampicillin; Cx, cefoxitin; C, chloramphenicol; Cip, ciprofloxacin; Cd, clindamycin; Cot, cotrimoxazole; E, erythromycin; Gen, gentamycin; Lz, linezolid; Ox, oxacillin; P, penicillin; Te, tetracycline (isolates intermediately resistant were included in the resistant category to determine their antimicrobial-resistant phenotypes).

TABLE 4: Antimicrobial resistance (MAR) index of $S$. aureus isolates $(n=74)$.

\begin{tabular}{lc}
\hline MAR indices & No. of S. aureus isolates (\%) \\
\hline 0 & $1(1.4)$ \\
0.08 & $1(1.4)$ \\
0.17 & $3(4.0)$ \\
0.25 & $3(4.0)$ \\
0.33 & $5(6.8)$ \\
0.42 & $5(6.8)$ \\
0.50 & $2(2.7)$ \\
0.58 & $10(13.5)$ \\
0.67 & $3(4.0)$ \\
0.75 & $4(5.4)$ \\
0.83 & $9(12.2)$ \\
0.92 & $26(35.1)$ \\
1 & $2(2.7)$ \\
Total & 74 \\
\hline
\end{tabular}

of the clinical laboratories in hospitals including nationallevel ones rely on biochemical tests to identify organisms. By using similar methods, other different studies conducted in Nepal had reported $S$. aureus as the predominant bacterial pathogen $[13,33,35,42]$; moreover, a high prevalence of $S$. aureus was also found in different parts of the world $[43,44]$. This variation may be due to the time, type of samples, and the geographical, seasonal/climatic condition $[44,45]$. The higher numbers of isolates $(47.1 \%)$ were obtained from wound swab followed by pus (41\%) and least from other samples (5.5\%). Similarly, Kandel et al. [46] showed $41.03 \%$ of S. aureus obtained from wounds followed by urine $(23.0 \%)$, pus $(20.5 \%)$, and blood (10.3\%), respectively. S. aureus is normally found in the environment and skin surface, so it is mostly obtained from wound swabs and pus.

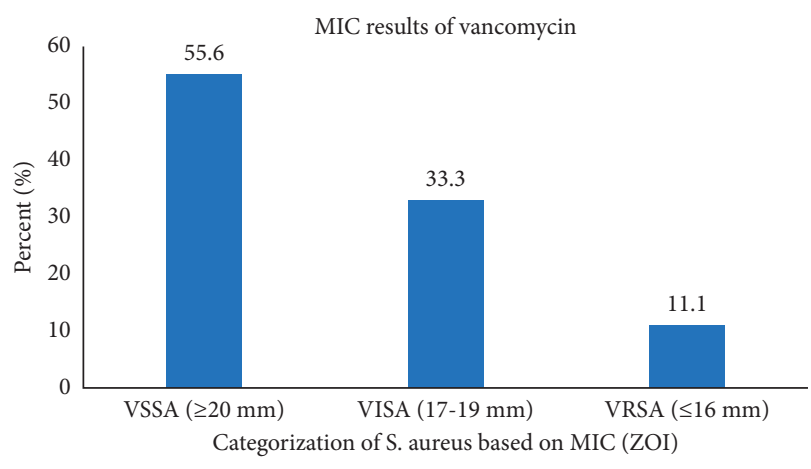

FIGURE 1: MIC result of vancomycin against MRSA isolates using an E-test strip (MIC; minimum inhibitory concentration, VSSA, vancomycin-sensitive $S$. aureus; VISA, vancomycin-intermediate $S$. aureus; VRSA, vancomycin-resistant $S$. aureus; and ZOI, zone of inhibition).

TABLE 5: Molecular screening of VRSA for vanA and vanB genes $(n=5)$.

\begin{tabular}{|c|c|c|c|c|}
\hline \multirow{2}{*}{ MSRA } & \multirow{2}{*}{$\begin{array}{l}\text { Screening } \\
\text { of } \\
\text { VRSA, } n \\
(\%)\end{array}$} & \multirow{2}{*}{$\begin{array}{c}\text { Confirmation of } \\
\text { VRSA by tde E-test, } \\
n(\%)\end{array}$} & \multicolumn{2}{|c|}{$\begin{array}{l}\text { Detection of VRSA } \\
\text { encoding genes }\end{array}$} \\
\hline & & & $\begin{array}{c}\operatorname{van} A, n \\
(\%)\end{array}$ & $\begin{array}{c}\operatorname{van} B, n \\
(\%)\end{array}$ \\
\hline 45 & $9(20.0)$ & & $2(40.0)$ & 0 \\
\hline
\end{tabular}

Furthermore, once MRSA or VRSA resides in a hospital and environment, it is arduous to get rid of it, and the hospital environment may serve as a source of nosocomial infections in the future too [47]. Therefore, early detection of those sorts of resistance genes such as van genes would be a useful tool for the identification of 


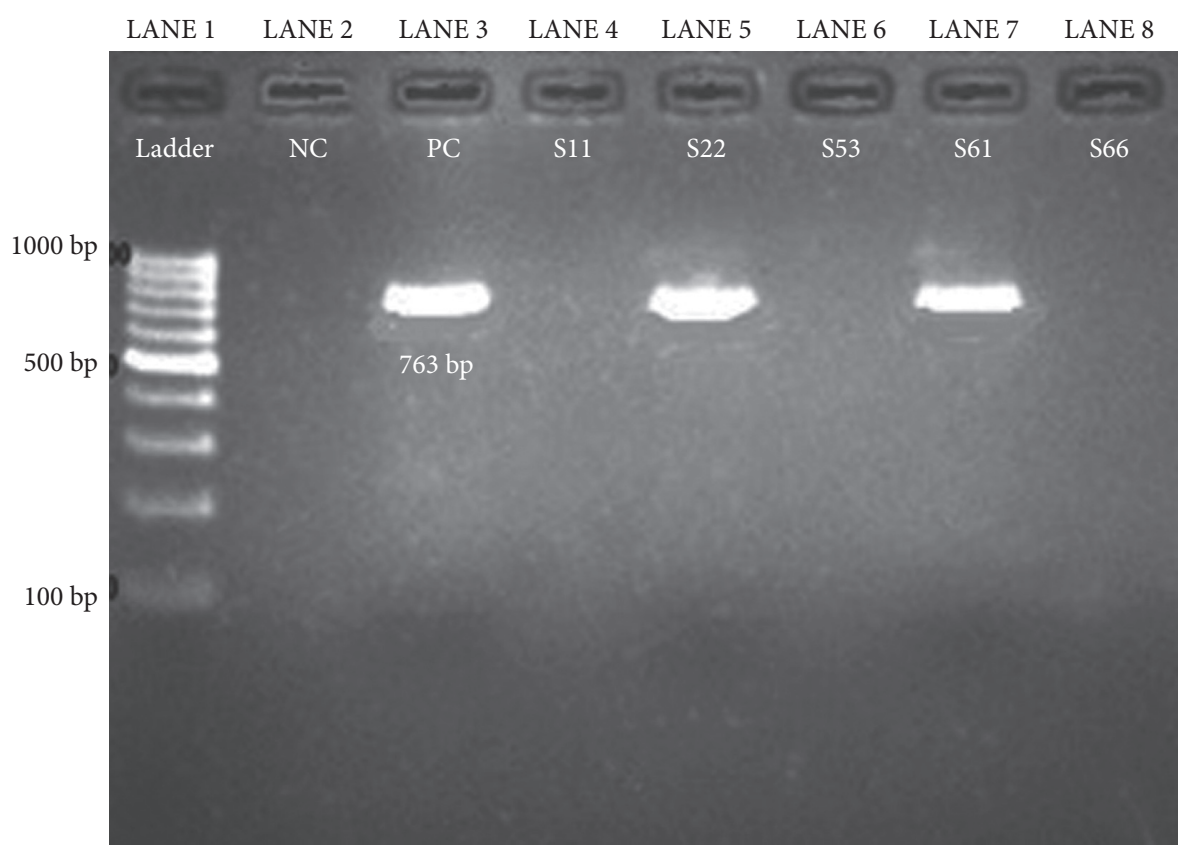

Figure 2: Amplification of the vanA gene from S. aureus isolates by conventional PCR (L1, DNA ladder 100-1000 bp; L2-NC, negative control; L3-PC, positive control; L4 to L8, S. aureus isolates; and S22 and S61 isolates were positive for the vanA gene).

infection and help in the prevention and control of their spread.

\section{Conclusions}

Detection of the vanA gene among MRSA isolates in our study alarms the spreading of the vancomycin-resistant gene among $S$. aureus and other bacterial pathogens. Moreover, the development of resistance to vancomycin, one of the few antibiotics available to treat MRSA infections, poses a serious problem in therapeutic management. However, linezolid could still be a choice of drug for the treatment of such infections.

\section{Data Availability}

The datasets generated and analyzed will be available on request to the corresponding author.

\section{Additional Points}

The study was conducted in a single setting for six months with 795 samples. So, the generalization of the findings may not be accurate. In addition, this study was a self-funded research, and we did not have enough funds to detect all van genes among MRSA isolates. However, based on the literature review, VRSA isolates, which harbor vanA and vanB genes, were the most common phenotypes, so we did focus on these two genes.

\section{Ethical Approval}

The ethical consideration was obtained from the Nepal Health and Research Council (NHRC) (Regd. No. 542/
2018). All methods were carried out following relevant guidelines and regulations.

\section{Consent}

Written informed consent was obtained from all the participants before sample collection.

\section{Conflicts of Interest}

The authors have no conflicts of interest.

\section{Authors' Contributions}

All authors made substantial contributions to conception and design of the study, acquisition of data, or analysis and interpretation of data and took part in drafting the manuscript or revising it. All authors had read and approved the final version of the manuscript and agreed to submit to the current journal.

\section{Acknowledgments}

The authors would like to thank all the staff in the microbiology department of KCMS and ANIAS for their kind cooperation and support to complete this research work.

\section{References}

[1] E. Gradelski, L. Valera, L. Aleksunes, D. Bonner, and J. FungTomc, "Correlation between genotype and phenotypic categorization of staphylococci based on methicillin susceptibility and resistance," Journal of Clinical Microbiology, vol. 39, no. 8, pp. 2961-2963, 2001.

[2] M. Tolera, D. Abate, M. Dheresa, and D. Marami, "Bacterial nosocomial infections and antimicrobial susceptibility pattern 
among patients admitted at hiwot fana specialized university hospital, eastern Ethiopia," Advances in medicine, vol. 2018, Article ID 2127814, 2018.

[3] E. Ghoniem, G. El Hendawy, T. Abdel Moteleb, H. Hassan, and H. El Refai Khalil, "Characterization of vancomycinresistant Staphylococcus aureus in the national liver Institute," Menoufia Medical Journal, vol. 27, no. 4, pp. 825-832, 2014.

[4] M. P. Jevons, ““Celbenin"-resistant staphylococci," BMJ, vol. 1, no. 5219, pp. 124-125, 1961.

[5] A. S. Lee, H. de Lencastre, J. Garau et al., "Methicillin-resistant Staphylococcus aureus," Nature Reviews Disease Primers, vol. 4, no. 1, p. 18033, 2018.

[6] K. Hiramatsu, H. Hanaki, T. Ino, K. Yabuta, T. Oguri, and F. C. Tenover, "Methicillin-resistant Staphylococcus aureus clinical strain with reduced vancomycin susceptibility," Journal of Antimicrobial Chemotherapy, vol. 40, no. 1, pp. 135-136, 1997.

[7] B. P. Howden, J. K. Davies, P. D. R. Johnson, T. P. Stinear, and M. L. Grayson, "Reduced vancomycin susceptibility in Staphylococcus aureus, including vancomycin-intermediate and heterogeneous vancomycin-intermediate strains: resistance mechanisms, laboratory detection, and clinical implications," Clinical Microbiology Reviews, vol. 23, no. 1, pp. 99-139, 2010.

[8] Y. Wada, A. A. Irekeola, E. A. R. ENS et al., "Prevalence of vancomycin-resistant Enterococcus (VRE) in companion animals: the first meta-analysis and systematic review," $A n$ tibiotics, vol. 10, no. 2, 2021.

[9] Y. Cong, S. Yang, and X. Rao, "Vancomycin resistant Staphylococcus aureus infections: a review of case updating and clinical features," Journal of Advanced Research, vol. 21, pp. 169-176, 2020.

[10] K. Nichol, M. Sill, N. Laing, J. Johnson, D. Hoban, and G. Zhanel, "Molecular epidemiology of urinary tract isolates of vancomycin-resistant Enterococcus faecium from North America," International Journal of Antimicrobial Agents, vol. 27, no. 5, pp. 392-396, 2006.

[11] B. T. Bamigboye, O. A. Olowe, and S. S. Taiwo, "Phenotypic and molecular identification of vancomycin resistance in clinical Staphylococcus aureus isolates in osogbo, Nigeria," European Journal of Microbiology and Immunology, vol. 8, no. 1, pp. 25-30, 2018.

[12] WHO, WHO Model List of Essential Medicines, WHO, Geneva, Switzerland, 2017.

[13] S. Raut, K. Bajracharya, J. Adhikari, S. S. Pant, and B. Adhikari, "Prevalence of methicillin resistant Staphylococcus aureus in lumbini medical college and teaching hospital, palpa, western Nepal," BMC Research Notes, vol. 10, no. 1, p. 187, 2017.

[14] B. Shrestha, B. M. Pokhrel, and T. M. Mohapatra, "Phenotypic characterization of nosocomial isolates of Staphylococcus aureus with reference to MRSA," Journal of infection in developing countries, vol. 3, no. 7, pp. 554-560, 2009.

[15] A. O. Kshetry, N. D. Pant, R. Bhandari et al., "Minimum inhibitory concentration of vancomycin to methicillin resistant Staphylococcus aureus isolated from different clinical samples at a tertiary care hospital in Nepal," Antimicrobial Resistance and Infection Control, vol. 5, no. 1, p. 27, 2016.

[16] S. P. Dumre, "Vancomycin-resistant Staphylococcus aureus (VRSA) from Nepal: a cocktail story," Nepalese Journal of Ophthalmology: A Biannual Peer-Reviewed Academic Journal of the Nepal Ophthalmic Society: NEPJOPH, vol. 4, no. 1, pp. 199-200, 2012.
[17] M. Cheesbrough, District Laboratory Practice in Tropical Countries, Cambridge University Press, Cambridge, UK, 2nd edition, 2005.

[18] B. A. Forbes, D. F. Sahm, A. S. Weissfeld, and W. R. Bailey, Bailey \& Scott's Diagnostic Microbiology, Elsevier Mosby, St. Louis, MO, USA, 2007.

[19] Clinical and Laboratory Standards Institute, Performance Standards for Antimicrobial Susceptibility Testing. 28th Ed. Informational Supplement M100-S28, Clinical and Laboratory Standards Institutei, Wayne: PA, USA, 2018.

[20] M. Cheesbrough, District Laboratory Practice in Tropical Countries, Cambdrige University Press, Cambridge, UK, Part 2, 2nd edition, 2006.

[21] G. S. Hall, "Bailey \& scott's diagnostic microbiology," Laboratory Medicine, vol. 44, no. 4, pp. e138-e139, 2013.

[22] E. U. Tuncan and S. E. Martin, "Lysostaphin lysis procedure for detection of Staphylococcus aureus by the firefly bioluminescent ATP method," Applied and Environmental Microbiology, vol. 53, no. 1, pp. 88-91, 1987.

[23] A. Azimian, S. A. Havaei, H. Fazeli et al., "Genetic characterization of a vancomycin-resistant Staphylococcus aureus isolate from the respiratory tract of a patient in a university hospital in northeastern Iran," Journal of Clinical Microbiology, vol. 50, no. 11, pp. 3581-3585, 2012.

[24] S. M. Clark and R. A. Mathies, "High-speed parallel separation of DNA restriction fragments using capillary array electrophoresis," Analytical Biochemistry, vol. 215, no. 2, pp. 163-170, 1993.

[25] S. Adkins and M. Burmeister, "Visualization of DNA in agarose gels as migrating colored bands: applications for preparative gels and educational demonstrations," Analytical Biochemistry, vol. 240, no. 1, pp. 17-23, 1996.

[26] S.-H. Kim, K.-H. Kim, H.-B. Kim et al., "Outcome of vancomycin treatment in patients with methicillin-susceptible Staphylococcus aureus bacteremia," Antimicrobial Agents and Chemotherapy, vol. 52, no. 1, pp. 192-197, 2008.

[27] S. J. van Hal and V. G. Fowler Jr., "Is it time to replace vancomycin in the treatment of methicillin-resistant Staphylococcus aureus infections?" Clinical Infectious Diseases, vol. 56, no. 12, pp. 1779-1788, 2013.

[28] A. Belbase, N. D. Pant, K. Nepal et al., "Antibiotic resistance and biofilm production among the strains of Staphylococcus aureus isolated from pus/wound swab samples in a tertiary care hospital in Nepal," Annals of Clinical Microbiology and Antimicrobials, vol. 16, no. 1, p. 15, 2017.

[29] R. R. Gurung, P. Maharjan, and G. G. Chhetri, "Antibiotic resistance pattern of Staphylococcus aureus with reference to MRSA isolates from pediatric patients," Future science $O A$, vol. 6, no. 4, p. Fso464, 2020.

[30] J. Sapkota, M. Sharma, B. Jha, and C. P. Bhatt, "Prevalence of Staphylococcus aureus isolated from clinical samples in a tertiary care hospital: a descriptive cross-sectional study," Journal of Nepal Medical Association, vol. 57, no. 220, pp. 398-402, 2019.

[31] B. Shakya, S. Shrestha, and T. Mitra, "Nasal carriage rate of methicillin resistant Staphylococcus aureus among at national medical college teaching hospital, birgunj, Nepal," Nepal Medical College Journal: NMCJ, vol. 12, no. 1, pp. 26-29, 2010.

[32] S. Ansari, H. P. Nepal, R. Gautam et al., "Threat of drug resistant Staphylococcus aureus to health in Nepal," BMC Infectious Diseases, vol. 14, no. 1, p. 157, 2014.

[33] L. K. Khanal and B. K. Jha, "Prevalence of methicillin resistant Staphylococcus aureus (MRSA) among skin infection cases at 
a hospital in Chitwan, Nepal," Nepal Medical College Journal: NMCJ, vol. 12, no. 4, pp. 224-228, 2010.

[34] N. Kumari, T. M. Mohapatra, and Y. I. Singh, "Prevalence of methicillin-resistant Staphylococcus aureus (MRSA) in a tertiary-care hospital in eastern Nepal," JNMA J Nepal Med Assoc, vol. 47, no. 170, pp. 53-56, 2008.

[35] A. Khanal, G. C. Sulochan, A. Khanal, R. Estrada, R. Ghimire, and S. Panthee, "Methicillin-resistant Staphylococcus aureus in Nepal: a systematic review and meta-analysis," International Journal of Infectious Diseases, vol. 103, pp. 48-55, 2021.

[36] C. J. Ghia, S. Waghela, and G. Rambhad, "A systemic literature review and meta-analysis reporting the prevalence and impact of methicillin-resistant Staphylococcus aureus infection in India," Infectious diseases, vol. 13, Article ID $1178633720970569,2020$.

[37] H. Boucher, L. G. Miller, and R. R. Razonable, "Serious infections caused by methicillin-resistant Staphylococcus aureus," Clinical Infectious Diseases, vol. 51, no. Suppl 2, pp. S183-S197, 2010.

[38] U. Lama, D. Shah, and U. T. Shrestha, "Vancomycin resistant Staphylococcus aureus reported from tertiary care hospital in Nepal," Tribhuvan University Journal of Microbiology, vol. 4, pp. 63-72, 2018.

[39] V. Thati, C. Shivannavar, and S. Gaddad, "Vancomycin resistance among methicillin resistant Staphylococcus aureus isolates from intensive care units of tertiary care hospitals in Hyderabad," Indian Journal of Medical Research, vol. 134, no. 5, pp. 704-708, 2011.

[40] O. Olufunmiso, I. Tolulope, and C. Roger, "Multidrug and vancomycin resistance among clinical isolates of Staphylococcus aureus from different teaching hospitals in Nigeria," African Health Sciences, vol. 17, no. 3, pp. 797-807, 2017.

[41] S. Saadat, K. Solhjoo, M.-J. Norooz-Nejad, and A. Kazemi, "VanA and VanB positive vancomycin-resistant Staphylococcus aureus among clinical isolates in shiraz, south of Iran," Oman Medical Journal, vol. 29, no. 5, pp. 335-339, 2014.

[42] M. Chaudhary, A. Bhattarai, S. K. Adhikari, and D. R. Bhatta, "Bacteriology and antimicrobial susceptibility of adult chronic dacryocystitis," Nepalese Journal of Ophthalmology: A Biannual Peer-Reviewed Academic Journal of the Nepal Ophthalmic Society: NEPJOPH, vol. 2, no. 2, pp. 105-113, 2010.

[43] Q. Ou, J. Zhou, D. Lin et al., "A large meta-analysis of the global prevalence rates of $S$. aureus and MRSA contamination of milk," Critical Reviews in Food Science and Nutrition, vol. 58, no. 13, pp. 2213-2228, 2018.

[44] H. Grundmann, D. M. Aanensen, C. C. van den Wijngaard, B. G. Spratt, D. Harmsen, and A. W. Friedrich, "Geographic distribution of Staphylococcus aureus causing invasive infections in Europe: a molecular-epidemiological analysis," PLoS Medicine, vol. 7, no. 1, Article ID e1000215, 2010.

[45] K. Sahoo, S. Sahoo, G. Marrone, A. Pathak, C. Lundborg, and A. Tamhankar, "Climatic factors and community - associated methicillin-resistant Staphylococcus aureus skin and softtissue infections - a time-series analysis study," International Journal of Environmental Research and Public Health, vol. 11, no. 9, pp. 8996-9007, 2014.

[46] S. N. Kandel, N. Adhikari, B. Dhungel et al., "Characteristics of Staphylococcus aureus isolated from clinical specimens in a tertiary care hospital, Kathmandu, Nepal," Microbiology Insights, vol. 13, Article ID 1178636120972695, 2020.

[47] M. Serra-Burriel, M. Keys, C. Campillo-Artero et al., "Impact of multi-drug resistant bacteria on economic and clinical outcomes of healthcare-associated infections in adults: systematic review and meta-analysis," PLoS One, vol. 15, no. 1, Article ID e0227139, 2020. 